\title{
Protection of the human research participant: A structured review
}

\author{
L Roets, $\mathrm{PhD}$ \\ Department of Health Studies, College of Human Sciences, University of South Africa, Pretoria
}

Corresponding author: L Roets (roetsl@unisa.ac.za)

The history of health research, and concerns about the protection of human participants, dates back as far as the 1800s. The regulation, legislation and ethics-review requirements regarding the protection of the human research participants cause lively debates among researchers and scientists. The objective of this article is to share the findings of a structured review that was aimed at investigating the impact of and challenges with regard to the legislation, governance and research regulations aimed at protecting human research participants. The thematic analysis of the findings revealed dissatisfaction with diverse operational practices; different legislation and regulation practices; and institutional governance. Simplified and universally agreed-upon regulations and operational practices are needed, as is a common understanding of all concepts relating to ethical research conduct.

S Afr Med J 2017;107(10):847-853. DOI:10.7196/SAMJ.2017.v107i10.12533

Research, and especially health research, benefits many people and communities, and sometimes society as a whole. Theoretical knowledge and the protection of the human participants are therefore justified, although the tension between scientific interests and the rights of individuals remains very prominent in discussions regarding research ethics. The Nuremberg Code and the Universal Declaration of Human Rights can be viewed as the bases for the development of universally accepted principles of research ethics that protect the human participant from harm and allow participants voluntary informed consent to the research. The Declaration of Helsinki, which is based on these, has therefore been recognised as one of the most authoritative statements on ethical standards for human research in the world. ${ }^{[1]}$

The greatest and most notorious tragedies in human research, such as the injection of people with an organism that caused yellow fever, led to the development of a 10-point memorandum, titled Permissible Medical Experimentation, by Drs Ivy and Alexander. The memorandum was a set of rules for research on human participants, and later became the Nuremburg Code. ${ }^{[1]}$

Researchers, however, have very diverse opinions of how a human participant is defined, and these divergent opinions have contributed to researchers claiming that they do not always have to seek ethical approval from a research ethics committee (REC) or institutional review board (IRB). However, the human participant, sometimes called the human subject, is defined by the South African (SA) National Department of Health $(\mathrm{DoH})^{[2]}$ as a living individual about whom a researcher obtains either (i) data, through interventions or interactions, or (ii) identifiable private information.

There is also ongoing debate about when research can be identified as health-related, and, consequently, subject to regulation and ethical approval before it can proceed, as researchers differ on how to classify their research, which determines whether or not they really need to go through the ethical review processes managed by RECs and IRBs. This is fuelled by differences in how each researcher defines health research.

According to the $\mathrm{DoH},{ }^{[2]}$ health research includes any research that contributes to the knowledge of biological or social processes in human beings; suggests improved methods of provision of health services; examines human pathology, the causes of disease or the effects of the environment on the human body; or contributes to the development of new applications of pharmaceuticals, medicines and related substances, or the development of new applications of health technology.

The implication of this broad interpretation is that almost all healthrelated or social-science research involves a human participant. This interpretation of how a human participant is defined, and of what constitutes health research, has resulted in widespread discomfort and dissatisfaction with the model that currently governs research at most modern universities, which requires all health researchers to obtain ethical approval from RECs or IRBs. ${ }^{[3]}$ Some researchers are of the view that ethics-review committees create a moral panic by means of distorted claims about potential harms to participants. ${ }^{[3]}$

This structured review was motivated by these continual debates about what constitutes a human participant, and when research can be identified as health related, as well as other challenges, such as what type of research should be subjected to an ethics review process, and the impact that the legislation, governance and regulation of research by RECs and IRBs have on researchers, research and participants.

The review aims to give an account of the impacts of and challenges pertaining to the legislation, governance and regulations that are aimed at protecting human research participants in the research process.

\section{Methods \\ Data sources}

A structured review of published literature from 2011 to 2016 was conducted according to the Preferred Reporting Items for Systematic Reviews and Meta-analysis (PRISMA) framework. ${ }^{[4]}$ The extensive and inclusive literature search was conducted using EBSCOhost, MEDLINE and the University of South Africa (Unisa) Library. This ensured the development of a relevant and conclusive structured review. The search terms used were 'research ethics', 'human participants and research ethics', 'research ethics legislation', 'regulating research' and 'research ethics governance. The terms were applied both individually and in combination, in an attempt to generate as much relevant literature as possible, with the added benefit of reduced risk of bias. The search was conducted in December 2016 
with the assistance of a Unisa subject-specialist librarian. The search was confined to research and review articles published in English. All results were combined in order to prevent duplications.

\section{Selection criteria}

Studies and review articles reporting on ethics in research, research governance and legislation pertaining to the protection of human research participants were all included. Both qualitative and quantitative studies, as well as review articles, were included, to enhance generalisability and the validity of the outcome of the review. Nine studies were included in this review.

\section{Assessment of study quality}

I adopted a global assessment tool that divided the studies into two categories, namely weak and strong, as described by Bradbury-Jones et al. ${ }^{[5]}$ The assessment tool was developed from the findings of a qualitative metasynthesis project. ${ }^{[6]}$ The appraisal instrument focused on several key elements, including clear aims and objectives, a clear description of the data gathering and analysis processes, triangulation of data and clearly formulated findings (Table 1). The overall quality appraisal of the studies focused on methodological strengths and weaknesses, but also on the relevance of the research or review to addressing the aim of this review.

\section{Data abstraction and assessment of risk bias}

The major outcomes of all the studies included were individually extracted by the researcher and the co-coder, using a structured approach. The data extracted related to the aims of the studies or reviews, the methodology, the participants, the settings and the key findings.

\section{Results}

The initial search retrieved 95 articles, which were then handscreened by title and abstract. This process resulted in 45 articles for possible inclusion. A step-by-step approach was then followed to identify the final nine included in this review (Fig. 1).

\section{Description of the studies}

The nine studies included all focused on the regulation, legislation and governance of research ethics, or on RECs aimed at protecting human participants, and the implications thereof for research and researchers (Table 2).

In the study by Gremillion et al., ${ }^{[7]}$ comparison was made between the operational practices of 10 RECs in New Zealand, in an attempt to identify best-practice options. In-depth narratives focusing on the tension between ethical decision-making as a regulatory activity, and researcher participation, and on researcher engagement in the decision-making processes, were obtained from a representative of each committee. The findings revealed that the RECs differ significantly in operational practices. Their levels of engagement with researchers, and with other committee members, differ widely. Gremillion et al. ${ }^{[7]}$ were of the opinion that RECs should balance their collaboration with researchers with governance and oversight, and that a one-size-fits-all approach would not suffice. They considered that there ought to be a balance between the controlling and the enabling functions of RECs.

Monaghan et al. ${ }^{[8]}$ found that seeking research ethics approval in the humanities and social sciences has become overloaded by bureaucratic rules and regulations. Their review was conducted in England with the purpose of: augmenting existing literature that critiques research ethics governance; showcasing the problems encountered when multisite approval must be obtained; and assessing the cost of bureaucratic procedures in ethics approval. Narratives and literature were used for the review. They found that some researchers and authors were of the opinion that research ethics regulations are

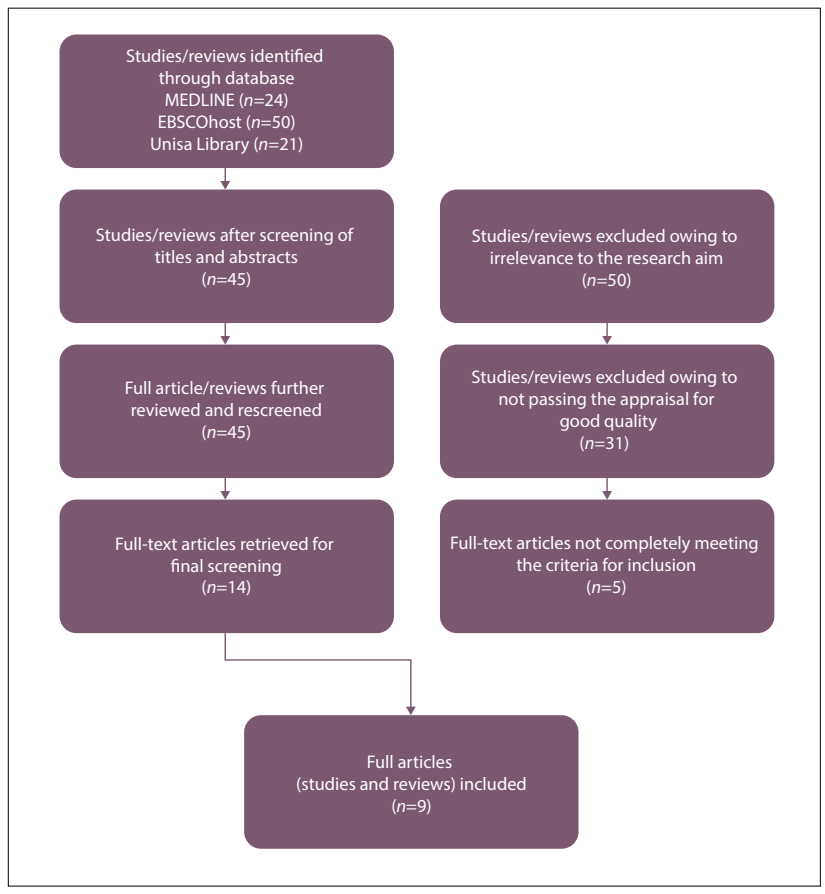

Fig. 1. Selection process for included studies/reviews.

Table 1. Assessment of study quality

\begin{tabular}{|c|c|c|c|c|c|c|}
\hline & Study & Overall quality & $\begin{array}{l}\text { Clear aims and } \\
\text { objectives }\end{array}$ & Ethical clearance & $\begin{array}{l}\text { Clear data } \\
\text { gathering and } \\
\text { analysis }\end{array}$ & $\begin{array}{l}\text { Clear findings } \\
\text { and conclusions }\end{array}$ \\
\hline 1 & Gremillion et al. ${ }^{[7]}$ & Good & Yes & NI & Yes & Yes \\
\hline 2 & Monaghan et al..$^{[8]}$ & Good & Yes & Yes & Yes & Yes \\
\hline 3 & McAreavey and Muir ${ }^{[3]}$ & Good & Yes & NI & Yes & Yes \\
\hline 4 & Brunger and Russel ${ }^{[9]}$ & Good & Yes & Yes & Yes & Yes \\
\hline 5 & Stühlinger and Hackl ${ }^{[10]}$ & Good & Yes & NI & Yes & Yes \\
\hline 6 & De Smit et al. ${ }^{[11]}$ & Good & Yes & Yes & Yes & Yes \\
\hline 7 & Silverman et al. ${ }^{[12]}$ & Good & Yes & Yes & Yes & Yes \\
\hline 8 & Macdonald and Spiegel ${ }^{[13]}$ & Good & Yes & NI & Yes & Yes \\
\hline 9 & Spencer et al. ${ }^{[14]}$ & Good & Yes & Yes & Yes & Yes \\
\hline
\end{tabular}


Table 2. Summary of included studies

\begin{tabular}{|c|c|c|c|c|c|}
\hline Study & $\begin{array}{l}\text { Country/ } \\
\text { setting }\end{array}$ & Methods & Participants & Aim/purpose & Findings \\
\hline $\begin{array}{l}\text { Gremillion } \\
\text { et al. }{ }^{[7]}\end{array}$ & New Zealand & $\begin{array}{l}\text { Qualitative } \\
\text { narratives }\end{array}$ & 10 members of RECs & $\begin{array}{l}\text { To compare the review } \\
\text { processes followed in } 10 \\
\text { RECs }\end{array}$ & $\begin{array}{l}\text { Processes followed differ; committees } \\
\text { must function within particular } \\
\text { constraints, and balance the } \\
\text { collaboration with researchers with } \\
\text { ethical research governance }\end{array}$ \\
\hline $\begin{array}{l}\text { Monaghan } \\
\text { et al. }{ }^{[8]}\end{array}$ & England & $\begin{array}{l}\text { Literature and } \\
\text { narratives }\end{array}$ & $\begin{array}{l}\text { Literature and } \\
\text { narratives from } \\
\text { researchers }\end{array}$ & $\begin{array}{l}\text { To add to literature on the } \\
\text { opinion of social researchers } \\
\text { on research ethics } \\
\text { governance }\end{array}$ & $\begin{array}{l}\text { Ethical regulation is fundamentally } \\
\text { wrong because the damage that is } \\
\text { caused to a democratic society far } \\
\text { exceeds any possible harm to a human } \\
\text { participant }\end{array}$ \\
\hline $\begin{array}{l}\text { McAreavey } \\
\text { and Muir }\end{array}$ & Austria & $\begin{array}{l}\text { Literature and } \\
\text { narratives }\end{array}$ & $\begin{array}{l}\text { Authors, REC } \\
\text { members, research } \\
\text { applicant, supervisor, } \\
\text { university } \\
\text { administrator }\end{array}$ & $\begin{array}{l}\text { To describe the issues that } \\
\text { have contributed to the } \\
\text { dissatisfaction with the } \\
\text { ethical review model that } \\
\text { is prevalent in a specific } \\
\text { university }\end{array}$ & $\begin{array}{l}\text { A collaborative approach rather than a } \\
\text { regulatory process needs to be adopted; } \\
\text { meaningful meetings with researchers, } \\
\text { reviewers and potential participants } \\
\text { will require extra time }\end{array}$ \\
\hline $\begin{array}{l}\text { Brunger } \\
\text { and Russel }{ }^{[9]}\end{array}$ & Canada & $\begin{array}{l}\text { Participatory } \\
\text { action research }\end{array}$ & Academic researchers & $\begin{array}{l}\text { To describe the politics } \\
\text { of community identity } \\
\text { and the implications for } \\
\text { re-imagining Canadian } \\
\text { ethics guidelines }\end{array}$ & $\begin{array}{l}\text { Collective consent requires careful } \\
\text { negotiation and should not be } \\
\text { simplified to make it look like } \\
\text { individual consent }\end{array}$ \\
\hline $\begin{array}{l}\text { Stühlinger } \\
\text { and Hackl }{ }^{[10]}\end{array}$ & Austria & Structured review & $\begin{array}{l}\text { Literature, policies } \\
\text { and legislation }\end{array}$ & $\begin{array}{l}\text { To provide an overview } \\
\text { of European regulations } \\
\text { in the field of ethics } \\
\text { review committees, review } \\
\text { requirements and Austrian } \\
\text { legislation }\end{array}$ & $\begin{array}{l}\text { European laws widely differ pertaining } \\
\text { to research with human subjects, } \\
\text { other than in medical research; in } \\
\text { some countries, one central REC } \\
\text { exists, others rely on local committees } \\
\text { and some on institutional-related } \\
\text { committees }\end{array}$ \\
\hline $\begin{array}{l}\text { De Smit } \\
\text { et al. } .^{[1]]}\end{array}$ & Australia & $\begin{array}{l}\text { Observational } \\
\text { study/ document } \\
\text { review }\end{array}$ & $\begin{array}{l}\text { Review of research } \\
\text { submissions, } \\
\text { paperwork and } \\
\text { correspondence } \\
\text { from RECs of } 25 \\
\text { departments across } \\
\text { seven Australian } \\
\text { states }\end{array}$ & $\begin{array}{l}\text { To describe the } \\
\text { heterogeneity in } \\
\text { documentation and } \\
\text { administration required } \\
\text { by Human Research Ethics } \\
\text { Review Committees and } \\
\text { Research Governance }\end{array}$ & $\begin{array}{l}\text { The diverse expectations from } \\
\text { RECs create a heavy workload in } \\
\text { requiring widespread ethical approval; } \\
\text { unnecessary administration must be } \\
\text { avoided and the processes simplified }\end{array}$ \\
\hline $\begin{array}{l}\text { Silverman } \\
\text { et al. } .^{[12]}\end{array}$ & $\begin{array}{l}\text { Egypt, SA } \\
\text { and India }\end{array}$ & $\begin{array}{l}\text { Quantitative } \\
\text { research using an } \\
\text { online assessment } \\
\text { tool to gather data }\end{array}$ & $\begin{array}{l}\text { Chairpersons of } \\
\text { RECs in India, Egypt } \\
\text { and SA }\end{array}$ & $\begin{array}{l}\text { To assess the usefulness of } \\
\text { a self-assessment tool in } \\
\text { obtaining data on the extent } \\
\text { to which RECs comply with } \\
\text { international standards }\end{array}$ & $\begin{array}{l}\text { The self-assessment tool can serve as } \\
\text { a quality-improvement tool to assist } \\
\text { in enhancing the operations of a } \\
\text { committee }\end{array}$ \\
\hline $\begin{array}{l}\text { Macdonald } \\
\text { and } \\
\text { Spiegel }^{[13]}\end{array}$ & USA and SA & Case study & $\begin{array}{l}\text { One researcher's } \\
\text { experience of } \\
\text { northern and } \\
\text { southern RECs }\end{array}$ & $\begin{array}{l}\text { To describe how the power } \\
\text { of institutional structures in } \\
\text { the global North and South } \\
\text { affect the work of students } \\
\text { trying to conduct research }\end{array}$ & $\begin{array}{l}\text { The REC failed to understand } \\
\text { qualitative research; they criticise the } \\
\text { way in which another REC approved a } \\
\text { study, insist on changes not approved } \\
\text { by the other REC }\end{array}$ \\
\hline $\begin{array}{l}\text { Spencer } \\
\text { et al. }{ }^{[14]}\end{array}$ & SA & $\begin{array}{l}\text { Multisite case } \\
\text { study using } \\
\text { interview guides } \\
\text { and focus groups }\end{array}$ & $\begin{array}{l}32 \text { participants from } \\
\text { three sites }\end{array}$ & $\begin{array}{l}\text { To describe the perceptions, } \\
\text { experiences and concerns } \\
\text { of } 32 \text { research stakeholders } \\
\text { regarding data-sharing } \\
\text { practices }\end{array}$ & $\begin{array}{l}\text { The key concern in data sharing is } \\
\text { informed consent }\end{array}$ \\
\hline
\end{tabular}

not fit for the purpose of research. Sociologists argued that ethical regulation is fundamentally wrong, because the damage that is caused to a democratic society by inhibiting research far exceeds any possible harm that can come to a human participant in research. The findings revealed a concern that ethics regulations and governance will kill social-science research, as differences in the opinions and procedures of different RECs can cause months of delays in obtaining ethics approval. 
McAreavey and Muir ${ }^{[3]}$ found widespread dissatisfaction with the ethical-review model at Australian universities. In this study, multiple perspectives were gained through discussions with a REC member, a researcher, a supervisor, a research applicant and a university administrator, who each related their own experiences regarding the ethics-review process. The researchers found that the RECs, in themselves, do not behave unethically, but they follow a model that results in the inappropriate treatment of applications. The findings revealed that academics often feel that they have to 'play the game' in order to obtain ethics approval, resulting in RECs not being treated with respect. Major difficulties were encountered with REC members who come from a natural- and physical-science background, as they found it hard to understand qualitative research.

Brunger and Russel's ${ }^{[9]}$ Canadian study was conducted with the aim of identifying how best to apply the Tri-Council Policy Statement guidelines in a community with complex and multiple political and cultural jurisdictions. Legislation (the Health Research Ethics Authority Act, SNL, 2006 Chapter H-1.2) had replaced regional-based review boards with centralised research ethics boards on a provincial level. All applications for health-research ethics approval now have to go through a centralised provincial review board. Participatory-action research was conducted, with research academics as participants. The findings revealed that far more collaboration is needed between researchers and boards, and that researchers and research ethics review board members should pay attention to the politics of risk in other words, the ways in which collective identity and research are co-constructed. To simplify collective consent as equal to individual consent was considered inappropriate, and misleading to both the researcher and the communities participating in a study.

Stühlinger and $\mathrm{Hackl}^{[10]}$ conducted a structured review in Austria to provide an overview of European regulations in the field of ethics-review committees, specifically their review requirements. They critically analysed Austrian legislation and proposed an institutional solution to address legislative gaps. The keywords used in their research were 'human research subject protection', 'research participant protection', 'research ethics committees' 'biomedical research' and 'European clinical trials regulation'. The findings revealed that European laws differ widely when it comes to research with human subjects, except for those concerning medical research. In some countries, a central research ethics committee exists, while in others there are local committees, and still others use institution-related committees. Some European countries have passed comprehensive laws on human research, but this is not necessarily so in others. It seems that research participants, therefore, are not equally protected.

Twenty-five departments from seven states in Australia participated in the study conducted by de Smit et al. ${ }^{[11]}$ The study purpose was to describe the heterogeneity in the administration and documentation required by human RECs across Australia. An observational study was made of the submission paperwork required by the various RECs, as well as the correspondence between the committees and the researchers from each of the collaborating sites. All participating states except Victoria employed a single ethics-review model; however, the application process, the guidelines provided for the number of documents needed for submission and the turnaround time varied significantly. The researchers concluded that these differences contributed to a very heavy workload in obtaining ethical approval, and that there is a need to simplify the processes.

Silverman et al. ${ }^{[12]}$ conducted a quantitative descriptive study using an online self-assessment tool to gather data from REC members in Egypt, India and SA. The purpose of their study was to assess whether a self-assessment tool could be used to obtain data that reveal the extent to which RECs comply with recognised international standards. The findings revealed that RECs in India, Egypt and SA mostly performed well at aspects such as submission processes, the recording of minutes, the use of recommended criteria for review of protocols and informed-consent documentation. The aspects identified as challenging were policies and procedures, membership composition, ethics training, procedures for proposal reviews, elements in decision letters and criteria for further review.

The dilemma of students or researchers who need ethics approval from RECs at different institutions (global North and South) were investigated in a case study by Macdonald and Spiegel. ${ }^{[13]}$ The study highlighted the frustrations experienced when a researcher receives approval from one committee, while a second committee insists on changes to the research proposal before it can be approved. Either the proposal must go back and forth between the various RECs, or the researcher has to be unethical by changing the proposal without the first REC knowing about the changes.

Spencer et al. ${ }^{[14]}$ conducted a multisite case study involving 32 research stakeholders, who took part in interviews and focusgroup discussions. The purpose was to describe their perceptions, experiences and concerns about data-sharing practices. Some participants suggested that the argument should move beyond the question of whether or not to share data, to how to share it in ways that best minimises potential harm and respects participants' reasonable expectations, such that the benefits would outweigh the potential harm. Junior researchers felt that more specific consent is needed if the purpose of the research deviates from that to which original consent was given. Senior researchers favoured broad consent for practical and administrative purposes. However, it seems that informed consent remains the key concern.

\section{Methodology quality}

All the studies included in this review had specific and clear aims and objectives. In six publications, the authors explicitly mentioned that ethical approval was received, and written consent obtained from the participants. In two publications, the qualitative data was provided by the authors themselves, and therefore they did not provide evidence of ethical approval to share their own experiences. The two review publications also did not indicate that ethical approval to conduct their studies was obtained. In some publications, the researchers and authors themselves were the participants, and in others the participants were either conveniently or purposefully selected. Gremillion et al., ${ }^{[7]}$ McDonald and Spiegel ${ }^{[13]}$ and McAreavey and Muir ${ }^{[3]}$ purposefully selected participants (the authors themselves) and undertook a thematic analysis of their narratives. Spencer et al. ${ }^{[14]}$ made use of snowball sampling and used thematic analysis. Silverman et al. ${ }^{[12]}$ purposefully selected chairpersons of RECs, and a statistical analysis of the data was done. Stühlinger and Hackl $^{[10]}$ conducted a structured review, with a thematic analysis, to present their data. Brunger and Russel, ${ }^{[9]}$ Monaghan et al ${ }^{[8]}$ and De Smit et al. ${ }^{[11]}$ purposefully selected participants and provide a thematic analysis of their data. Kasule et al. ${ }^{[15]}$ sent an open invitation to all administrators of RECs in Africa whose contact details were available on the internet, and provided a statistical analysis of the data. Most of the studies reported on qualitative data, which was not a surprise, as it seems that it is mostly researchers involved in social-science research who are concerned about the legislation and regulation of research to protect the human research participant. All studies provided clear findings that contributed to the findings of this structured review. 


\section{Results}

The thematic analysis of the results of the included studies revealed three themes: operational practices, legislation and regulation, and organisational governance (Table 3 ).

\section{Operational practices}

It is evident from the review findings that the operational practices of RECs and IRBs are very diverse, ${ }^{[7]}$ although they all strive to protect the human participant. For the researcher who needs to obtain ethical approval from different committees around the globe, this is a frustration, as such inconsistencies can be a hindrance that does not enhance research or contribute to a global culture of research. The submission requirements, communication and collaboration between the committees and researchers, and the meeting procedures and review processes, are different for each committee. ${ }^{[7,11]}$ The National Health and Medical Council in Australia has developed a national approach, but this intervention has not streamlined the process. ${ }^{[1]}$ The disparities were clearly highlighted when the same study was submitted to 24 RECs, and the feedback differed significantly; there were between 0 to more than 10 major concerns raised by the various committees, and the turnaround time for resubmission ranged from 2 weeks to 2 months. ${ }^{[1]}$ Sometimes, ethical approval took as long as 1 year, or a specific REC did not grant such approval at all, which forced researchers to go to alternative committees to obtain ethical approval for their study. ${ }^{[8]}$ These delays in turn cause delays in data gathering and graduation, and can have serious implications with regard to funding and so forth. It seems that inflexible and prescribed rules to protect human participants, without supportive structures and relevant procedures, lead to frustration for researchers. Some researchers defiantly stated that 'breaking the rules imposed on researchers by RECs will not result in unethical behaviour'.[8]

Although very specific training is required for REC members, ${ }^{[8]}$ most of this training is focused on the committee chairpersons. ${ }^{[15]}$
Not all members are equally capacitated to undertake an objective review that protects the human participant without harassing the researcher, which inhibits a positive and ethical culture of research Training is needed to simplify, but also to homogenise, human research ethics approval processes, ${ }^{[11]}$ to protect not only the human participant, but also the researcher.

\section{Legislation and regulation}

Legislation and regulation differ from country to country, ${ }^{[13]}$ and various registration and accreditation bodies exist. Some countries have passed comprehensive laws on human-subject research (Spain, Cyprus, Switzerland, Denmark, Norway, Luxembourg, Latvia, Estonia, Lithuania and SA), while this is not the case in others. ${ }^{[10]}$ In the USA, IRBs are registered with the US Office for Human Research Protections, in an attempt to simplify and co-ordinate research ethics approval.

In certain countries, all health ethics research committees must be accredited or registered with a National Health Research Council or other relevant institution. ${ }^{[16]}$ Some countries extend their responsibility to also cover the social and behavioural sciences. ${ }^{[13]}$ In some countries, such as SA, the National Health Act (Act No. 61 of 2003) requires that RECs be registered with a national body, and it also prescribes the criteria for membership and the expertise of members of a REC, and provides guidelines with regard to the training of committee members, as well as standing operational procedures. ${ }^{[2]}$

RECs should facilitate the ethics review process and protect the rights and dignity of potential human research participants, and prevent inconsistency in the interpretation of guidelines ${ }^{[1]}$ and definitions. It is also imperative that concepts such as 'vulnerable human subjects', 'health research' and 'personal data' are universally understood and agreed upon, to determine whether an ethics review is required or not - not all research involves a human participant or sensitive data. ${ }^{[10]}$

Receiving ethical approval for research in the humanities and social sciences has become increasingly problematic due to the bureaucratic

Table 3. Themes identified

\begin{tabular}{|c|c|c|}
\hline Theme & Category & Subtheme \\
\hline \multirow[t]{9}{*}{ Operational practices } & Submission requirements & Application documents \\
\hline & & Application processes \\
\hline & Communication & Contact persons \\
\hline & & Timeframes \\
\hline & Meetings & Online \\
\hline & & Face to face \\
\hline & & Regularity \\
\hline & Review processes & Training requirements \\
\hline & & Expertise \\
\hline \multirow[t]{9}{*}{ Legislation and regulation } & Diverse accreditation and registration bodies & National Health Research Councils, institutional boards, \\
\hline & & Department of Health \\
\hline & & Acts \\
\hline & Different definitions of human participants & \\
\hline & Positive aspects & $\begin{array}{l}\text { Ethical decision-making, } \\
\text { protection of the human participant }\end{array}$ \\
\hline & Negative aspects & Negative impact on social research \\
\hline & & Governing the researcher \\
\hline & & Unpredictable ethical decision-making \\
\hline & & Power games \\
\hline \multirow[t]{4}{*}{ Institutional governance } & Constraints & Lack of resources \\
\hline & & Diverse departments \\
\hline & & Lack of clear mandate \\
\hline & & Inconsistency in the application of governance \\
\hline
\end{tabular}


rules and regulations. ${ }^{[8]}$ The fact that ethical decision-making is inherently local, very specific, contextual and also contestable also implies that it cannot easily be accommodated in a bureaucratic system of rules. ${ }^{[8]}$

Some researchers felt that the ethical-review process was a power game, which felt like an emotional war. ${ }^{[8]}$ Unpredictable and inconsistent ethical reviews and results, ${ }^{[1]]}$ as well as inappropriate treatment of researchers, ${ }^{[3]}$ cause the abovementioned experiences of researchers.

Researchers are confronted with the tensions between their own ethical conscience and all the procedural demands of rules, regulations ${ }^{[8]}$ and legislation, causing negativity towards pursuing research where human participation is involved.

A question raised by researchers was: who is a REC protecting when it insists that a separate, local ethics approval process cannot alter or recommend alterations on a research proposal approved by them? ${ }^{[13]}$

\section{Institutional governance}

To develop a culture in research that supports ethical conduct requires unconditional support and commitment from the leaders of an institution. It is essential that every member of the REC demonstrates transparency, integrity and accountability. Adequate resources, legitimatising the authority of a committee and compliance with national laws ${ }^{[12]}$ are crucial.

In many African countries, a lack of financial resources to strengthen the capacity of the REC membership is a major challenge ${ }^{[15]}$ The administrative duties involved in the ethics review process contribute to a heavy workload for both the researcher and the REC members, and therefore there is a general call to reduce the number of administrative processes and procedures. ${ }^{[1]}$

Inconsistency in the application of governance ${ }^{[1]}$ is also a problem. University governance is and should be affected by the requirements for accreditation by or registration with a national body when the requirements are gazetted, as for example in SA.

The parameters of ethical regulation are often determined by the demands of funders ${ }^{[3]}$ The global tendency is that research grants can only be obtained after approval from a formal REC or IRB, ${ }^{[3]}$ without researcher or participant ever having a say in what they consider ethical or otherwise. This raises serious questions about who is currently protected by all the regulatory processes. ${ }^{[17]}$

\section{Limitations of the review}

The fact that the authors in four of the nine studies included in this review used their own research experience as data, thereby contributing to the narratives used for data gathering, might be construed as biasing their conclusions, but the contexts were very clearly described and their personal experiences were carefully examined. It is interesting to note that although all the studies were concerned with the issue of gaining ethical approval, four publications did not indicate whether or not their studies were ethically approved.

\section{Conclusion}

The types of research that require ethical approval have changed over time, from a focus purely on medical research, to the inclusion of new fields such as public-health research, biomedical research and other health-related fields. As a result, there is a need for new ethical standards to be established that equally protect all human participants, as well as researchers. In Europe and many other countries around the globe, national laws, as yet, have not been adapted to reflect this change, or its impact on the protection of human participants. ${ }^{[10]}$ These challenging developments require the establishment of new ethical-review principles.

An ethics review is intended to be a transparent process that makes a positive contribution to the research itself and the culture of research in general, and that ensures the protection of human participants, but instead, the introduction of ethical scrutiny has incurred hostility. ${ }^{[3]}$ Research should not be separated from ethical requirements, but it seems that REC regulations have raised concerns and ignited lively debate.

To behave ethically means to protect others, minimise harm and increase the sum of good in the world. A REC, as a multidisciplinary, independent body charged with reviewing research proposals involving human participants, must ensure that the dignity, rights and wellbeing of human participants are protected. However, there are many more concerns in research than merely the protection of the human participant. Issues that cause contention in the power relationship between committee and researcher are: the choice of research questions; the relative distribution of burdens v. benefits; the ownership of data; the appreciation of intellectual capital; capacity building; and respect not only for local IRBs, RECs ${ }^{[13]}$ and committee members, but also researchers.

REC reviews should maintain and promote confidence, and guarantee transparency, in research, by protecting the rights of participants ${ }^{[10]}$ and of the researcher. However, qualitative researchers perceive the ethical approval process as a hurdle to be overcome, and do not, in any way, view it as a collegial process that is there to support them. The relationship between a REC and a researcher should be one of mutual trust, and initiatives such as an international network, similar to UNESCO, to support and co-operate with researchers and ethics committees, ${ }^{[10]}$ should be considered.

There is also a need for diverse RECs from all over the world to interact and agree on what ethical research entails. ${ }^{[13]}$ The abundance of research data that exists today, as well as the technology to distribute and make these data available, has enormous potential to contribute to advances in science ${ }^{[14]}$ and to an interrelated and diversified health-research environment. Policies that mandate that researchers share their data are becoming common, ${ }^{[18]}$ but how does this affect consent by participants and the ownership of the data? Commentators have advocated for the protection of the rights and the responsibilities of the researcher who is generating the data, while recognising the rights of the data assessors, ${ }^{[14]}$ but where do these leave the human participants who gave consent to a specific study? These are the issues that ethics committees need to consider.

The major differences in the standards of different RECs and IRBs also complicate international research collaboration, research funding and the publication of research findings. Differences in the interpretations of the concepts 'human participant', 'health-related research', 'vulnerable group' and 'sensitive private data' contribute to the frustration of researchers, especially in the social sciences, where researchers conducting collaborative research must adapt their research to conform to the requirements of diverse committees and boards to obtain approval.

In addition to the lively debate around the various interpretations of the concepts mentioned above, there are other pertinent issues that need further investigation, such as the types of research that can be considered as involving human participants; the definition of health-related research; the diversity of RECs and their requirements; the lack of a global simplified process; the delays in obtaining approval; and the legislation, regulation and governance of research and research ethics, RECs and the protection of human participants. 
This structured review left me with a feeling of discomfort. Although human research participants must be protected, researchers and research should equally be supported and motivated. The ethicsreview process must be streamlined; the concepts need to be clear, well defined and transparent; and the process must contribute to capacity building. It should not be hostile to researchers, and must be carried out by knowledgeable and trained committee members, and overall, enhance a culture of ethical conduct in research.

The question that I am still left with is: Is it possible for RECs around the globe to agree on one simplified, streamlined process that encourages a positive culture of research, while protecting the human research participant and the community as a whole?

\section{Acknowledgements. None. \\ Author contributions. Sole author. \\ Funding. None.}

Conflicts of interest. None.

1. Dhai A. The research ethics evolution: From Nuremburg to Helsinki. S Afr Med J 2014;14(3):178-180.

http://doi.org/10.7196/SAMJ.7864
2. National Department of Health, South Africa. Ethics in health research: Principles, structures and National Department of Health, South Africa. Ethics in health research: Principles,
procedures. http://www.mrc.ac.za/ethics/DOHEthics.pdf (accessed 10 March 2017).

3. McAreavey R, Muir J. Research ethics committees: Values and power in higher education. Int J Soc Res Methodol 2011;14(5):391-405. http://doi.org/10.1080/13645579.2011.565635

4. Moher D, Liberati A, Tetzlaff J, Altman DG \& The PRISMA Group. Preferred reporting items for systematic reviews and meta-analysis: The PRISMA statement. Open Med 2009;3(3):123-130. http:// doi.org/10.1371/journal.pmed.1000097

5. Bradley-Jones C, Rattray J, Jones M, MacGillivray S. Promoting the health, safety and welfare of adults with learning disabilities in acute care settings. A structured literature review. J Clin Nurs 2013; 22:1479-1509. http://onlinelibrary.wiley.com/doi/10.1111/jocn.12109/pdf (accessed 10 March 2017). 6. Sandelowski M, Barroso J. Classifying the findings in qualitative studies. Qual Health Res 2003;13(7):905923. http://journals.sagepub.com/doi/10.1177/1049732303253488 (accessed 10 March 2017).
7. Gremillion H, Snell D, Crosthwaite J, Finch B, Paterson J, Tavinor G. What does organizational diversity in New Zealand tertiary sector research ethics committees teach us about balancing consultative and governance approaches to ethics review? N Z Sociol 2016;31(4):4-27. http://search.informit.com.au/fu governance approaches to ethics review? N Z Sociol 2016;31(4):4-27.
llText:dn=339248951923644:res=IELFSC (accessed 10 March 2017).

8. Monaghan LF, O'Dwyer M, Gabe J. Seeking university research ethics committee approval: The emotional vicissitudes of a 'rationalised' process. Int J Soc Res Methodol 2013;16(1):65-80. https://doi org/10.1080/13645579.2011.649902

9. Brunger F, Russel T. Risk and representation in research ethics: The NunatuKavut experience. J Empir Res Hum Res Ethics 2016;10(4):368-379. https://doi.org/10.1177/1556264615599687

10. Stühlinger V, Hackl M. Research ethics committees in the field of health-related human research - a European perspective and the case of Austria. Eur J Health Law 2014,21:387-400. http://booksandjournals. brillonline.com/content/journals/10.1163/15718093-12341329 (accessed 10 March 2017).

11. De Smit E, Kearns LS, Clarke L, Dick J, Hill CL, Hewitt AW. Heterogeneity of human research ethics committees and research governance offices across Australia: An observational study. Australas Med J 2016;9(2):33-39. https://doi.org/10.4066/AMJ.2015.2587

12. Silverman $\mathrm{H}$, Sleem $\mathrm{H}$, Moodley K, et al. Results of a self-assessment tool to assess the operational characteristics of research ethics committees in low and middle- income countries. J Med Ethics 2015;41:332-337. http://doi.org/10.1136/medethics-2013-101587

13. Macdonald $\mathrm{H}$, Spiegel AD. Distraction from the real difficulties: Ethical deliberations in international Macdonald H, Spiegel AD. Distraction from the real difficulties: Ethical deliberations in international
health research. Anthropol S Afr 2013;36(3-4):146-154. http://doi.org/10.1080/02580144.2013.10887040 Spencer G, Silaigwana B, Wassenaar D, Bull S, Parker M. Developing ethical practices for public health 4. Spencer G, Silaigwana B, Wassenaar D, Bull S, Parker M. Developing ethical practices for public health
research data sharing in South Africa: The views and experiences from a diverse sample of research research data sharing in South Africa: The views and experiences from a diverse sample of research
stakeholders. J Empir Res Hum Res Ethics 2015;10(3):290-301. http://journals.sagepub.com/doi/ stakeholders. J Empir Res Hum Res Ethics 2015;10(3):
abs/10.1177/1556264615592386 (accessed 10 March 2017).

15. Kasule M, Wassenaar DR, Ijsselmuiden C, Mockatla B. Silent voices: Current and future roles of African research ethics committee administrators. IRB Ethics Hum Res 2016;38(1):13-19. http:/ www.cohred.org/wp-content/uploads/2012/09/Silent-Voices-Current-and-Future-Roles-of-AfricanResearch.pdf (accessed 10 March 2017).

6. South Africa. National Health Act No. 61 of 2003. http://www.gov.za/sites/www.gov.za/files/a61-03. pdf (accessed 10 March 2017)

17. Watson R, Gelling L. Editorial: NHS research ethics committees: For whose protection? J Clin Nurs 2012;21:2097-2098. http://onlinelibrary.wiley.com/doi/10.1111/j.1365-2702.2011.03887.x/epdf (accessed 10 March 2017).

18. Department of Health and Human Services, National Institutes for Health, USA. NIH Genomic data Department of Health and Human Services, National Institutes for Health, USA. NIH Genomic data
sharing, 2014. https://www.nih.gov/news-events/../nih-issues-finalized-policy-genomic-data-sharing (accessed 14 February 2017)

Accepted 16 May 2017 